\section{Using Humus on Golf Course Fairways to Alleviate Soil Salinity Problems}

\author{
Huisen $\mathrm{Zhu}^{1}$ and Deying $\mathrm{Li}^{2,3}$
}

ADDITIONAL INDEX WORDs. organic matter recycled water, salt, saline, topdressing, turfgrass

SUMMARY. Increased use of recycled water along with inherent soil salinity problems on golf courses make salinity an important issue for golf course management. The objective of this study was to investigate if using humus on golf fairways by topdressing or spraying can alleviate soil salinity problems and improve turf quality. The study was conducted from 2015 to 2017 at Aurora, CO, and Medora, ND. Treatments included an untreated control, topdressing (sand, sand + peat), and spraying of humic acid. Our results showed that the application of humus increased the soil microbial biomass and improved turf quality on fairways either with a soil salinity problem or irrigated with recycled water. The effects on turfgrass health and turf quality were dependent on the rates of humus applied. Humic acid at $3 \mathrm{gal} / \mathrm{acre}$ was equivalent to topdressing sand + peat $(80 / 20 \mathrm{v} / \mathrm{v})$ and consistently showed improved turf quality over the untreated control. Soil properties also were affected by the application of humus. Soil $\mathrm{pH}$, electrical conductivity (EC), bulk density, water infiltration, and microbial biomass may have had an indirect contribution to turf quality.

$\mathrm{B}$ ased on a national survey, golf courses in the United States used 2.3 million acre-ft of irrigation water per year during 2004-05, with $12 \%$ of all golf facilities using recycled water as one of the water sources (Throssell et al., 2009). Recycled water usage increased from $14.7 \%$ in 2005 to $\approx 25 \%$ in 2013 of all water used on golf courses (Gelernter et al., 2015). Most recycled water has elevated salt levels (Harivandi, 2007; Marcum, 2006). Golf courses that are developed on saline soils or where the major water sources contain high salt levels also experience salinity problems. Salts cause physiological stress on turfgrasses (Slavens et al., 2009) and have negative effects on soil properties including structure, water movement, and nutrient availability (Murphy, 2015; Qian and Mecham, 2005). Therefore, increased use of recycled water along with inherent soil salinity problems on many golf

This research was partially funded by the United States Golf Association (USGA), the grant from the key research development program of Shanxi Province (No. 201603D221017-2), and the Hatch Project ND01558.

${ }^{1}$ College of Animal Science and Veterinary Medicine, Shanxi Agricultural University, Taigu, Shanxi 030801, China

${ }^{2}$ Department of Plant Sciences, North Dakota State University, Fargo, ND 58108

${ }^{3}$ Corresponding author. E-mail: deying.li@ndsu.edu. https://doi.org/10.21273/HORTTECH03989-18 courses make salinity an important issue in golf course management.

Soil salinity causes soil organic matter (OM) flocculation, which leads to OM loss due to wind erosion and leaching (Artiola and Walworth, 2009; Kida et al., 2017; Martinez et al., 2002; Wong et al., 2010). Salinity not only accelerates the decrease of soil OM but also increases the accumulation of harmful trace elements in plants (Ondrasek et al., 2012), inhibits the microbial activity in soils (Setia et al., 2014), and delays the decomposition of soil organic residues (Peinemann et al., 2005). Soil properties deteriorate as OM diminishes (Wong et al., 2010) because soil $\mathrm{OM}$ is important for nutrient recycling, cation exchange capacity, water holding, and structure stability. When dealing with soil salinity problems in land management, different practices are taken to improve soil $\mathrm{OM}$ quality and quantity. Examples of such include reclamation with grasses (Akhter et al., 2004), addition of glucose (Elmajdoub et al., 2014) or plant residues (Hasbullah and Marschner, 2015; Wong et al., 2009), and incorporation of compost to soil (Wright et al., 2008).

Salinity is more problematic on fairways than on putting greens and tee boxes on a golf course because greens and tees are usually constructed with sand-based root zones and drainage systems, which allow for efficient leaching of salts. Fairways, which contribute to the largest playing surface on a golf course, are usually maintained on native soils with limited drainage. Because of the relative large area, topdressing, and aeration may not be affordable on fairways even though the practices are shown to be beneficial (Klingenberg et al., 2013). The objective of this study was to test if application of humus on golf course fairways by topdressing or spray can alleviate soil salinity problem and improve turf quality.

\section{Materials and methods}

The study was conducted from 2015 to 2017 on two golf courses. During 2015 and 2016, the study was on the 17th fairway of the Valley Country Club (VCC) in Aurora, CO. The fairway was covered predominantly with kentucky bluegrass (Poa pratensis), with negligible amounts of annual bluegrass (Poa annua), and perennial ryegrass (Lolium perenne) and was aerated (solid tine of $3 / 4$-inch diameter and 6 inches deep) in Apr. 2015. For both 2015 and 2016 , the fairway received $1 \mathrm{lb} / 1000$ $\mathrm{ft}^{2}$ nitrogen $(\mathrm{N})$ from urea stabilized with dicyandiamide and $\mathrm{N}$-(n-butyl) thiophosphoric triamide (UMaxx; J.R. Simplot Co., Boise, ID) in April, $0.5 \mathrm{lb} / 1000 \mathrm{ft}^{2} \mathrm{~N}$ from ammonium sulfate monthly from June to

\begin{tabular}{llll}
\hline $\begin{array}{l}\text { Units } \\
\text { To convert U.S. to SI, } \\
\text { multiply by }\end{array}$ & U.S. unit & SI unit & $\begin{array}{l}\text { To convert SI to U.S., } \\
\text { multiply by }\end{array}$ \\
\hline $1,233.4819$ & acre- $\mathrm{ft}$ & $\mathrm{m}^{3}$ & 0.0008 \\
0.3048 & $\mathrm{ft}$ & $\mathrm{m}$ & 3.2808 \\
9.3540 & gal/acre & $\mathrm{L} \cdot \mathrm{ha}^{-1}$ & 0.1069 \\
2.54 & inch $(\mathrm{es})$ & $\mathrm{cm}$ & 0.3937 \\
48.8243 & $\mathrm{lb} / \mathrm{l}, 000 \mathrm{ft}^{2}$ & $\mathrm{~kg} \cdot \mathrm{ha}^{-1}$ & 0.0205 \\
1.1209 & $\mathrm{lb} / \mathrm{acre}$ & $\mathrm{kg} \cdot \mathrm{ha}^{-1}$ & 0.8922 \\
1 & $\mathrm{mmho} / \mathrm{cm}$ & $\mathrm{dS} \cdot \mathrm{m}^{-1}$ & 1 \\
28.3495 & $\mathrm{oz}$ & $\mathrm{g}$ & 0.0353 \\
1.7300 & $\mathrm{oz} / \mathrm{inch}^{3}$ & $\mathrm{~g} \cdot \mathrm{cm}^{-3}$ & 0.5780 \\
1 & $\mathrm{ppm}$ & $\mathrm{mg} \cdot \mathrm{kg}^{-1}$ & 1
\end{tabular}


October, and $200 \mathrm{lb} /$ acre langbeinite in April and August. The langbeinite contained $22 \%$ potassium $(\mathrm{K}), 22 \%$ sulfur $(\mathrm{S})$, and $11 \%$ magnesium $(\mathrm{Mg})$. No pesticides were applied during the 2 -year period of study. The turfgrass was mowed at 0.65 inch. Recycled water from a local water treatment plant was used for irrigation (Table 1 ). The VCC hosts about 29,000 rounds of play per year.

During 2016 and 2017, the study was on the first fairway of the Bully Pulpit Golf Course (BPGC) in Medora, ND. The fairway was covered predominantly with kentucky bluegrass with less than $5 \%$ of perennial ryegrass and fine-leafed fescues (Festuca sp.). Fertilization was $2.0 \mathrm{lb} /$ $1000 \mathrm{ft}^{2} \mathrm{~N}$ annually using $20 \mathrm{~N}-$ $0.9 \mathrm{P}-16.6 \mathrm{~K}$ in three applications; May at $0.75 \mathrm{lb} / 1000 \mathrm{ft}^{2}$, July at 0.5 $\mathrm{lb} / 1000 \mathrm{ft}^{2}$, and September at 0.75 $\mathrm{lb} / 1000 \mathrm{ft}^{2}$. Gypsum, containing $20 \%$ calcium ( $\mathrm{Ca}$ ), was applied at $750 \mathrm{lb} / 1000 \mathrm{ft}^{2}$ monthly from May to September. A selective herbicide containing 2,4-D, mecoprop, and dicamba (Three-Way; LESCO, Roswell, GA) was applied in late May at the labeled rate. The mowing height of the fairway was 0.65 inch. Well water was pumped to a pond before being used for turfgrass irrigation (Table 1 ). The BPGC hosts about 17,000 rounds of play per year.

Initial soil and water samples were taken from two study sites at the end of April or the beginning of May and were analyzed by commercial laboratories (Table 1). The two study sites followed the same research protocol. Treatments included topdressing with sand, sand + reed sedge peat $(90 / 10 \mathrm{v} / \mathrm{v})$, sand + reed sedge peat $(80 / 20 \mathrm{v} / \mathrm{v})$, and sprayable humic substance (REV; Dakota Peat, Grand Forks, ND) at 1 and $3 \mathrm{gal} /$ acre, and an untreated control. The reed sedge peat contained $>90 \%$ OM. The sprayable humic substance was a suspension with particle sizes smaller than $100 \mu \mathrm{m}$, and containing $21.2 \%$ humic acid and $0.8 \%$ fulvic acid based on dry weight. Each treatment plot measured $20 \times 50 \mathrm{ft}$. The treatments were arranged in a randomized complete block design with three replications. The sand at the VCC site had an EC of $0.65 \mathrm{dS} \cdot \mathrm{m}^{-1}$ and a composition of $8.2 \%$ very coarse, $35.3 \%$ coarse, $44.3 \%$ medium, $11.9 \%$ fine, $0.1 \%$ very fine, and $0.2 \%$ silt and clay. The sand at the BPGC site had an EC of $1.2 \mathrm{dS} \cdot \mathrm{m}^{-1}$ and a composition of $3.8 \%$ very coarse, $20.8 \%$ coarse, $42.0 \%$ medium, $29.4 \%$ fine, $3.7 \%$ very fine, and $0.3 \%$ silt and clay. Treatments were applied in the first week of May, July, and September each year. Topdressing was applied at $1 / 8$-inch depth. Humus was sprayed at a spray volume of $30 \mathrm{gal} / \mathrm{acre}$.

Soil properties and turf quality were evaluated on day 15 or 16 of each month, from May to September in each year. Soil $\mathrm{pH}$ was tested in a $1: 1$ soil/deionized water $(\mathrm{v} / \mathrm{v})$. Soil EC was determined in a $1: 5$ soil/ deionized water $(\mathrm{v} / \mathrm{v})$ extract. Soil $\mathrm{OM}$ was determined using loss-onignition method (Ben-Dor and Banin, 1989). Soil bulk density was determined from each plot using an undisturbed soil sampler (A-145; ELE Intl., Loveland, CO) at the 2.9- to $8.9-\mathrm{cm}$ depth below the turf surface to avoid sampling the thatch and mat layer which was less compacted. Soil samples were oven-dried at $105{ }^{\circ} \mathrm{C}$ for $24 \mathrm{~h}$ before the determination of dry bulk density. Water infiltration rate was measured using the falling-head, double-ring method with the diameter of inner and outer rings being 10 and $15 \mathrm{~cm}$, respectively. Two sub samples were taken from each plot. Water infiltration rate was recorded when the change was less than $5 \%$ over 5 -min periods following the principles of Bouwer (1986). Soil microbial biomass carbon (MBC) was determined by fumigation-extraction (Anderson and Ingram, 1993). Briefly, $5 \mathrm{~g}$ of soil was extracted with $0.5 \mathrm{M}$ potassium sulfate in $1: 4$ ratio $(\mathrm{v} / \mathrm{v})$ for both nonfumigated and chloroformfumigated samples. Dissolved organic carbon in the extracts was determined by titration with $0.033 \mathrm{M}$ acidified ferrous ammonium sulfate after dichromate digestion of the extraction. The MBC concentration was calculated from the difference between the fumigated and nonfumigated samples and multiplying the difference by 2.64 (Vance et al., 1987).

Turf visual quality was evaluated using a 1 to 9 scale (National Turfgrass Evaluation Program, 2000), where 9 is the best, 6 is the minimum acceptable, and $\mathrm{l}$ is completely dead turf. The turfgrass was scanned at $1 \mathrm{~m}$ above the ground with a handheld data collection and mapping unit (model 505

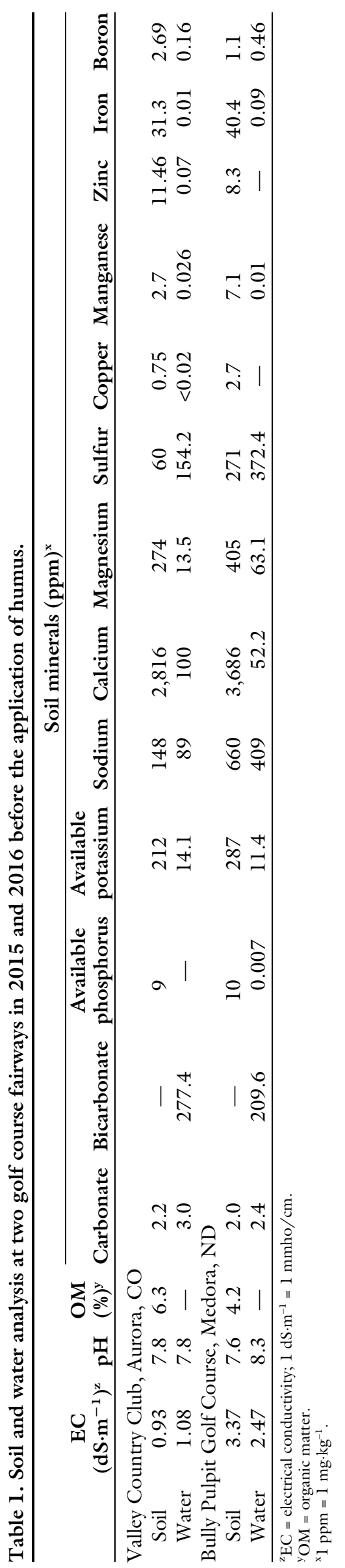


Greenseeker; Trimble, Hamilton, IN), which collects near-infrared light (NIR) at $770 \mathrm{~nm}$ and red light (Red) at $660 \mathrm{~nm}$. Turfgrass normalized vegetation index (NDVI) was calculated from the spectrum radiance data using the following formula: $\mathrm{NDVI}=(\mathrm{NIR}-\mathrm{Red}) /(\mathrm{NIR}+\mathrm{Red})$.

Data were analyzed separately for two locations but within one location the data were combined for 2 years because of homogenous variation. The data homogeneity was tested by the HOVTEST option in the GLM procedure of SAS (version 9.3; SAS Institute, Cary, NC). Treatment means were separated using the Tukey's honestly significant difference test at the 0.05 P level.

\section{Results and discussion}

Turf Quality. At the VCC site, monthly turf quality was consistently higher for the humic acid treatment at 3 gal/acre as compared with the untreated control (Table 2). Treatments containing either peat or humic acid showed better turf quality than the untreated control in all months except May. Topdressing with straight sand improved turf quality over the control only in September. Treatments containing $20 \%$ peat or humic acid at $3 \mathrm{gal} /$ acre resulted in higher NDVI values than the untreated control, for all months except May, which is consistent with turf quality data. A previous study also showed that NDVI is a good indicator of stress levels in turfgrass and is strongly correlated with turf visual quality (Gao and $\mathrm{Li}, 2012$ ).

At the BPGC site, monthly turf quality was consistently higher for the humic acid treatment at $3 \mathrm{gal} / \mathrm{acre}$ as compared with sand topdressing or untreated control (Table 3). There were no differences in turf quality between the two rates of peat in topdressing except in August and September. Similarly, turf quality was not different between the two rates of humic acid except in September. The NDVI results also indicated that topdressing with sand + peat or spraying humic acid was more beneficial than untreated control or topdressing with sand only. The differentiations between the rates of peat and between the rates of humic acid were more noticeable for NDVI than for turf quality (Table 3). The light spectrumbased NDVI is indicative of leaf chlorophyll content because the index is reflective of light use efficiency by leaves, which is strongly correlated with leaf chlorophyll content (Ciganda et al., 2009).

At both study sites, application of humic acid at $3 \mathrm{gal} /$ acre caused either equivalent or better turf quality than topdressing sand + peat $(80 / 20 \mathrm{v} / \mathrm{v})$, although the latter provided more $\mathrm{OM}$ to the fairways as calculated from the dry weight. Therefore, the treatment differences were not only caused by the absolute amount of OM but also by the components in the OM as well as the application methods.

SoIL Property. At the VCC site, soil $\mathrm{pH}$ was lower than the control when the higher rate of peat or humic acid was used (Table 4). The soil EC responded differently to the

Table 2. Turf quality as affected by topdressing and humus application on a golf course fairway in Aurora, CO, during 2015 and 2016.

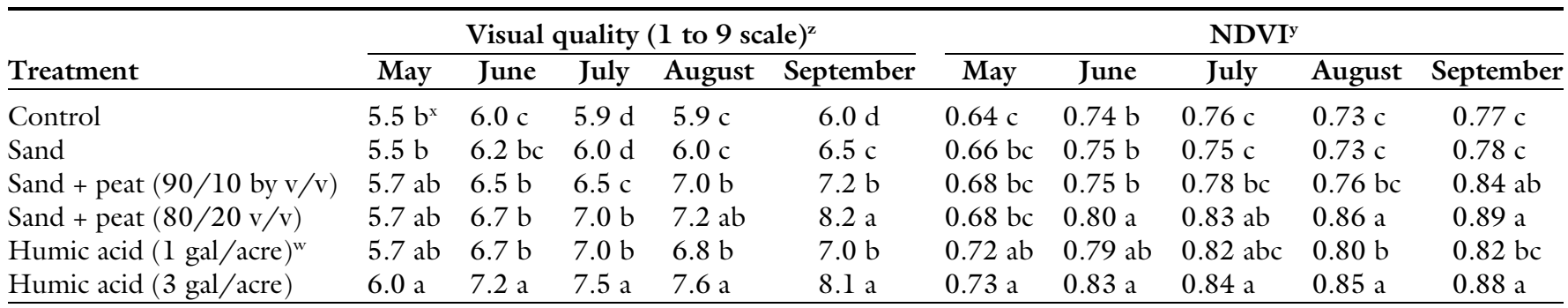

${ }^{\mathrm{z}}$ Turf visual quality was evaluated using a 1 to 9 scale (National Turfgrass Evaluation Program, 2000), where 9 is the best, 6 is minimum acceptable, and 1 is completely dead turf.

${ }^{y_{T}}$ Turfgrass normalized vegetation index (NDVI) using the formula: NDVI $=($ NIR - Red $) /($ NIR + Red $)$, where near-infrared light $($ NIR $)$ was at 770 nm and red light $($ Red $)$ was at $660 \mathrm{~nm}$.

${ }^{\mathrm{x}}$ Means within a column followed by the same letter are not significantly different at $P=0.05$ based on Tukey's honestly significant difference test.

${ }^{\mathrm{w}} \mathrm{l} \mathrm{gal} / \mathrm{acre}=9.3540 \mathrm{~L} \cdot \mathrm{ha}^{-1}$.

Table 3. Turf quality as affected by topdressing and humus application on a golf course fairway in Medora, ND during 2016 and 2017.

\begin{tabular}{|c|c|c|c|c|c|c|c|c|c|c|}
\hline \multirow[b]{2}{*}{ Treatment } & \multicolumn{5}{|c|}{ Visual quality ( 1 to 9 scale $)^{z}$} & \multicolumn{5}{|c|}{ NDVI $^{y}$} \\
\hline & May & June & July & August & September & May & June & July & August & September \\
\hline Control & $5.0 c^{x}$ & $5.4 \mathrm{c}$ & $5.6 \mathrm{~b}$ & $5.8 \mathrm{c}$ & $6.0 \mathrm{~d}$ & $0.50 \mathrm{c}$ & $0.54 \mathrm{c}$ & $0.65 \mathrm{~b}$ & $0.68 \mathrm{c}$ & $0.70 \mathrm{c}$ \\
\hline Sand + peat $(90 / 10 \mathrm{v} / \mathrm{v})$ & $6.0 \mathrm{ab}$ & $6.5 \mathrm{ab}$ & $6.7 \mathrm{a}$ & $6.8 \mathrm{~b}$ & $7.2 \mathrm{~b}$ & $0.56 \mathrm{~b}$ & $0.66 \mathrm{~b}$ & $0.76 \mathrm{a}$ & $0.79 \mathrm{~b}$ & $0.80 \mathrm{~b}$ \\
\hline Sand + peat $(80 / 20 \mathrm{v} / \mathrm{v})$ & $6.4 \mathrm{a}$ & $6.8 \mathrm{a}$ & $7.1 \mathrm{a}$ & $7.6 \mathrm{a}$ & $7.8 \mathrm{a}$ & $0.61 \mathrm{a}$ & $0.72 \mathrm{a}$ & $0.78 \mathrm{a}$ & $0.83 \mathrm{a}$ & $0.84 \mathrm{a}$ \\
\hline Humic acid (1 gal/acre) & $5.9 \mathrm{~b}$ & $6.2 \mathrm{~b}$ & $6.8 \mathrm{a}$ & $7.0 \mathrm{~b}$ & $7.2 \mathrm{~b}$ & $0.59 \mathrm{ab}$ & $0.68 \mathrm{ab}$ & $0.77 \mathrm{a}$ & $0.78 \mathrm{~b}$ & $0.77 \mathrm{~b}$ \\
\hline
\end{tabular}

${ }^{\mathrm{z}}$ Turf visual quality was evaluated using a 1 to 9 scale (National Turfgrass Evaluation Program, 2000), where 9 is the best, 6 is minimum acceptable, and 1 is completely dead turf.

${ }^{{ }^{y}}$ Turfgrass normalized vegetation index (NDVI) using the formula: NDVI $=(\mathrm{NIR}-\mathrm{Red}) /(\mathrm{NIR}+\mathrm{Red})$, where near-infrared light $(\mathrm{NIR})$ was at 770 nm and red light $($ Red $)$ was at $660 \mathrm{~nm}$.

${ }^{x}$ Means within a column followed by the same letter are not significantly different at $P=0.05$ based on Tukey's honestly significant difference test

${ }^{\mathrm{w}} 1 \mathrm{gal} / \mathrm{acre}=9.3540 \mathrm{~L} \cdot \mathrm{ha}^{-1}$. 
application of treatments in different months. In May and July, only topdressing with peat resulted in lower EC than the control, which could have been due to higher infiltration rates in those treatments. Topdressing with sand only did not lower the soil EC despite the higher infiltration rates because of the high salt content in sand. The higher water infiltration rates were accompanied by lower soil bulk density (Table 4). In September, the soil had a lower EC than the control as a result of topdressing and the use of humic acid at $3 \mathrm{lb} /$ acre.

At the BPGC site, soil $\mathrm{pH}$ was decreased by topdressing with sand + peat $(80 / 20 \mathrm{v} / \mathrm{v})$ or spraying with humic acid as compared with the control (Table 5). The $\mathrm{pH}$ change may be the result of more healthy turfgrass. The soil EC was the highest in sand topdressing because of the salt content in the topdressing sand. The increased water infiltration rates in topdressing treatments could be explained by the decrease in soil bulk density. Spraying humic acid did not affect soil EC as compared with the control.

At both study sites, application of humus caused a decrease in $\mathrm{pH}$ and increase of soil OM. However, the amount of change at VCC site was very small so that no conclusion can be made as to whether humus application had any direct impact on turf quality despite the statistical significance (Table 4). Because neither study site showed a large change in soil EC due to the application of humus, the contribution of EC to turf quality was not conclusive. There was not a single factor clearly responsible for the change in soil EC because salt content in the topdressing sand, changes of water infiltration rate, and the salinity levels in the irrigation water all played a role (Tables 1,4 , and 5 ).

Soil MBC was increased over the control due to the application of humus either as peat or as a spray (Tables 4 and 5). Humic acid at 3 gal/acre was equivalent to topdressing sand + peat $(80 / 20 \mathrm{v} / \mathrm{v})$ with respect to the effect on $\mathrm{MBC}$, and both treatments showed higher MBC than the lower rate of humic acid at 1 $\mathrm{gal} / \mathrm{acre}$.

\section{Conclusions}

Our results showed that the application of humus increased the soil

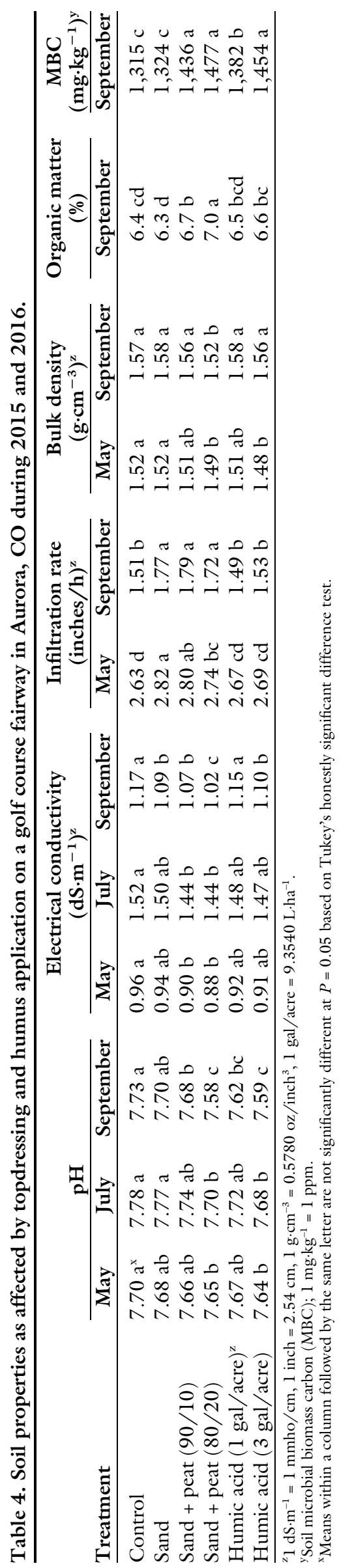


MBC and improved turf quality over the untreated soils on two fairways that had either an inherent soil salinity problem or was irrigated with recycled water with high salt content. The effects on turfgrass health and turf quality were dependent on the rates of humus. Despite the small value, the visual quality improvement over the untreated control at the VCC site was from unacceptable to acceptable value of six for most of the summer. At the BPGC site, application of humic substance improved turfgrass visual quality over the untreated control and sand topdressing alone. Soil microbial activity is critical to soil nutrient availability and is negatively affected by soil salinity. Therefore, maintaining sufficient soil $\mathrm{OM}$ is necessary to support the soil microbial activity and soil health over time. Soil properties also were affected by the application of humus and the effects on soil $\mathrm{pH}, \mathrm{EC}$, bulk density, and water infiltration were complicated because those factors are correlated. The quality of topdressing sand, especially salt content, was also an important factor for soil EC. Similar results were found at two golf courses with different climate, indicating that the findings may be applicable in areas of wide geological diversity.

\section{Literature cited}

Akhter, J., R. Murray, K. Mahmood, K.A. Malik, and S. Ahmed. 2004. Improvement of degraded physical properties of a saline-sodic soil by reclamation with kallar grass (Leptochloa fusca). Plant Soil 258:207-216.

Anderson, J.M. and J.S.I. Ingram. 1993. Tropical soil biology and fertility: A handbook of methods. CAB Intl., Wallingford, UK.

Artiola, J.F. and J.L. Walworth. 2009. Irrigation water quality effects on soil carbon fractionation and organic carbon dissolution and leaching in a semiarid calcareous soil. Soil Sci. 174:365-371.

Ben-Dor, E. and A. Banin. 1989. Determination of organic matter content in aridzone soils using a simple "loss-on-ignition" method. Commun. Soil Sci. Plant Anal. 20:1675-1695.

Bouwer, H. 1986. Intake rate: Cylinder infiltrometer, p. 825-844. In: A. Klute (ed.). Methods of soil analysis. Part 1 . Physical and mineralogical methods. 2nd ed. Agron. Monogr. 9. Amer. Soc. Agron., Soil Sci. Soc. Amer., Madison, WI.

Ciganda, V., A. Gitelson, and J. Schepers. 2009. Non-desctructive determination of maize leaf and canopy chlorophyll content. J. Plant Physiol. 166:157-167.

Elmajdoub, B., P. Marschner, and R.G. Burns. 2014. Addition of glucose increases the activity of microbes in saline soils. Soil Res. 52:568-574.

Gao, Y. and D. Li. 2012. Detecting salinity stress in tall fescue based on single leaf spectrum. Scientia Hort. 138:159-164.

Gelernter, W.D., L.J. Stowell, M.E. Johnson, C.D. Brown, and J.F. Beditz. 2015. Documenting trends in water use and conservation practices on U.S. golf courses. Crop Forage Turfgrass Mgt. doi:10.2134/cftm2015.0149.

Harivandi, M.A. 2007. Using recycled water on golf courses. Golf Course Mgt. 75(6):98-108.

Hasbullah, H. and P. Marschner. 2015. Residue properties influence the impact of salinity on soil respiration. Biol. Fert. Soils 51:99-111.

Kida, M., M. Tomostsune, Y. Iimura, K. Kinjo, T. Ohtsuka, and N. Fujitake. 2017. High salinity leads to accumulation of soil organic carbon in mangrove soil. Chemosphere 177:51-55.

Klingenberg, M.T., D. Li, N.E. Christians, and C.J. Blume. 2013. Core aeration programs and sand topdressing improve creeping bentgrass fairways. Intl. Turfgrass Soc. Res. J. 12:151-156.

Marcum, K.B. 2006. Use of saline and non-potable water in the turfgrass industry: Constraints and developments. Agr. Water Mgt. 80:132-146.

Martinez, R.S., P. Zalba, M.B. Villamil, and N. Peinemann. 2002. Organic matter mobilization as affected by soil solution composition and prevailing clay minerals. Commun. Soil Sci. Plant Anal. 33:2291-2299.

Murphy, B.W. 2015. Impact of soil organic matter on soil properties-A review with emphasis on Australian soils. Soil Res. 53:605-635.
National Turfgrass Evaluation Program. 2000. NTEP turfgrass evaluation guidelines. 1 May 2015. <http://www.ntep. org/pdf/ratings.pdf $>$.

Ondrasek, G., Z. Rengel, D. Romic, and R. Savic. 2012. Salinity decreases dissolved organic carbon in the rhizosphere and increases trace element phyto-accumulation. Eur. J. Soil Sci. 63:685-693.

Peinemann, N., G. Guggenberger, and W. Zech. 2005. Soil organic matter and its lignin component in surface horizons of salt-affected soils of the Argentinian Pampa. Catena 60:113-128.

Qian, Y.L. and B. Mecham. 2005. Longterm effects of recycled waste water irrigation on soil chemical properties on golf course fairways. Agron. J. 97:717-721.

Setia, R., P. Rengasamy, and P. Marschner. 2014. Effect of mono- and divalent cations on sorption of water-extractable organic carbon and microbial activity. Biol. Fert. Soils 50:724-734.

Slavens, M.R., A.M. Petrovic, and J.J. Barlow. 2009. The impact of recycled water irrigation on soil health and quality of newly established cool season turfgrass during drought conditions. Intl. Turfgrass Soc. Res. J. 11:471-480.

Throssell, C.S., G.T. Lyman, M.E. Johnson, G.A. Stacey, and C.D. Brown. 2009. Golf course environmental profile measures water use, source, cost, quality, and management and conservation strategies. Appl. Turfgrass Sci. doi: 10.1094/ATS-20090129-01-RS.

Vance, E., P. Brookes, and D. Jenkinson. 1987. An extraction method for measuring soil microbial biomass C. Soil Biol. Biochem. 19:703-707.

Wong, V.N.L., R.C. Dalal, and R.S.B. Greene. 2009. Carbon dynamics of sodic and saline soils following gypsum and organic material additions: A laboratory incubation. Appl. Soil Ecol. 41:29-40.

Wong, V.N.L., R.S.B. Greene, R.C. Dalal, and B.W. Murphy. 2010. Soil carbon dynamics in saline and sodic soils: A review. Soil Use Mgt. 26:2-11.

Wright, A.L., T.L. Provin, F.M. Hons, D.A. Zuberer, and R.H. White. 2008. Compost impacts on sodicity and salinity in a sandy loam turf grass soil. Compost Sci. Util. 16:30-35. 